\title{
Use of airway clearance therapy in children hospitalised with acute lower respiratory tract infections in a South African paediatric hospital
}

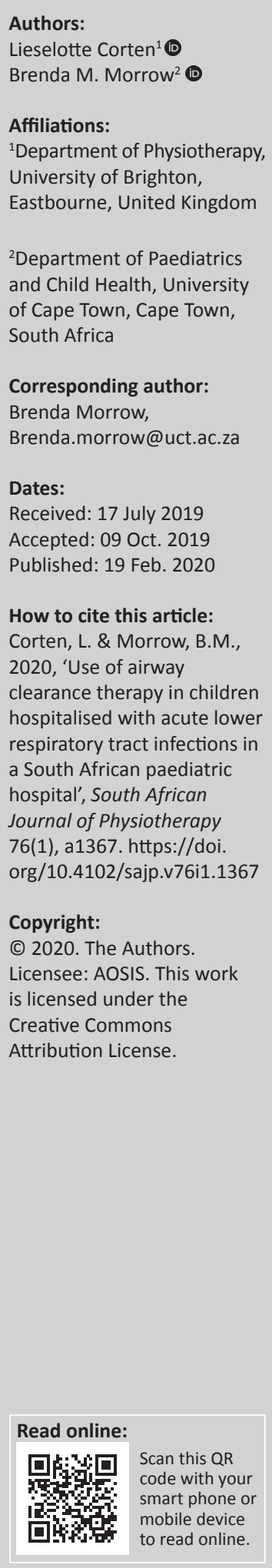

Background: Little is known about the prescription, frequency and nature of airway clearance therapy $(\mathrm{ACT})$ in children hospitalised with lower respiratory tract infections (LRTIs).

Objectives: To describe the characteristics and outcomes of children hospitalised with LRTIs at a tertiary paediatric hospital in South Africa and to investigate the role and impact of ACT in these children.

Method: A retrospective folder review of children hospitalised with LRTI between January and June 2015 was conducted, extracting data on demographic characteristics, health condition, ACT interventions and patient outcomes.

Results: A total of 1208 individual cases (median [IQR] age 7.6 (2.8-19.0) months), in 1440 hospitalisations, were included. The majority of children were hospitalised primarily for the management of bronchiolitis. Comorbidities were present in $52.6 \%$ of patients during at least one of their hospitalisations. Airway clearance therapy was administered in $5.9 \%(n=85)$ of admissions, most commonly conventional (manual) ACT. Transient oxyhaemoglobin desaturation was reported in six children, and one child developed lobar collapse an hour post-treatment. No other adverse events were reported. The median (IQR) duration of hospitalisation was 2.3 (1.5-5.0) days, and the overall mortality rate was $0.7 \%$. Children hospitalised for presumed nosocomial infections and pneumonia had the longest length of stay, were more likely to receive ACT and had the highest mortality rate.

Conclusion: Airway clearance therapy was infrequently used in this population and was more commonly applied in those with nosocomial LRTI and pneumonia.

Clinical implications: Although ACT was generally well tolerated, safety has not been ascertained, and oxygen saturation should be carefully monitored during therapy.

Keywords: respiratory tract infection; paediatrics; respiratory therapy; Southern Africa; chest physiotherapy.

\section{Introduction}

Lower respiratory tract infections (LRTIs), particularly pneumonia, are among the leading causes of mortality in children under 5 years of age worldwide (Liu et al. 2015:430-440). Respiratory disease may cause increased volume and viscosity of pulmonary secretions, ciliary dyskinaesia and ineffective cough, which may impair pulmonary secretion clearance with subsequent sequelae related to airway obstruction (Fink 2007:1210-1221). Physiotherapists can facilitate airway clearance using techniques that mobilise pulmonary secretions, known as airway clearance therapy (ACT) (Morrow 2019:1-12). These techniques can be passive techniques, performed manually by the therapist (e.g. positioning, percussions and vibrations), or active techniques requiring cooperation (e.g. the active cycle of breathing technique, autogenic drainage and positive expiratory pressure techniques) (Morrow 2019:1-12). Although ACT may be used in the clinical management of children with LRTIs, there is a lack of evidence regarding the safety and effectiveness of ACT in this population. In children hospitalised with pneumonia, contradicting results have been found regarding the effectiveness of ACT in this population (Abdelbasset \& Elnegamy 2015:219-226; Corten et al. 2018:e1690; Corten, Jelsma \& Morrow 2015:256; Lukrafka, Fuchs \& Fischer 2012:967-971; Moura Da Silva et al. 2015:eS1052-eS1053; Paludo et al. 2008:791-794). In children hospitalised with bronchiolitis, however, it is agreed that ACT should not be routinely applied (Caffrey Osvald \& Clarke 2015:1-3; Figuls et al. 2016:CD004873). A recently published state-of-the-art review concluded that ACT should not be performed 
routinely in children with LRTI but rather treatment should be prescribed on an individualised basis following clinical assessment (Morrow 2019:1-12).

There is little recent evidence available on current physiotherapy practices relating to the prescription, frequency and nature of ACT in children hospitalised with LRTIs, or investigating the adherence to guidelines. Furthermore, published data regarding adverse events associated with ACT in this context are also lacking.

This study aimed to describe the characteristics, health condition, course and outcome of children hospitalised with LRTIs at a tertiary paediatric hospital, with specific reference to the role and impact of ACT in these children.

\section{Materials and methods}

This was a retrospective folder review of routinely collected clinical data of children hospitalised at Red Cross War Memorial Children's Hospital (RCWMCH), Cape Town, South Africa, from January 2015 to June 2015, with a clinical diagnosis of any LRTI.

\section{Participants}

Children from birth to 18 years, admitted to any ward in RCWMCH, with any community- or hospital-acquired LRTI were eligible for inclusion. Folders were identified using primary diagnostic codes (ICD 10 codes) for a range of respiratory conditions or clinical signs of respiratory disease, and physiotherapy department records were used to identify patients who were referred for and/or received ACT during the study period.

\section{Instrumentation}

A standard pre-structured data extraction form, validated for content by two experts, was used to record data on demographic information, comorbid conditions, ACTs administered and any associated complications, and patient outcomes. No identifying information, except for folder number, was recorded during data extraction.

For cases with multiple admissions during the study period, demographic data were collected for the first admission only to avoid pseudo-replication.

\section{Data analysis}

Data were analysed using Statistica Version 13 (Statsoft Inc, USA). Data were tested for normality using the Lilliefors test. All numerical data are presented as either mean (standard deviation $[\mathrm{SD}]$ ) or median (interquartile range [IQR]), and proportions are presented as percentages. A Chi-squared test (with Yates test where appropriate) was performed to test for associations between categorical variables. The influence of all relevant variables on patient outcome measures was analysed using forward stepwise multiple regression analysis. A one-way ANOVA was performed to compare the length of hospitalisation amongst diagnostic groups.

\section{Ethical considerations}

Institutional ethical approval (HREC 717/2015) was obtained from the Human Research Ethics Committee (University of Cape Town) for the study. The need for written informed consent was waived owing to the retrospective study design.

\section{Results}

In total, 1756 cases were initially identified, of which 399 folders were duplicates and 1357 folders were screened for eligibility (Figure 1). Fifty-four folders were excluded as the child did not have an LRTI, and 93 folders were missing. Therefore, a total of 1208 patient folders were included in the descriptive folder review. Of these, 1038 patients (85.9\%) were hospitalised once between January and June 2015. The remaining 172 (14.2\%) were hospitalised multiple times during the study period.

\section{Demographic characteristics}

The demographic characteristics of the included children can be found in Table 1.

Of the 35 HIV-infected children, 29 (82.9\%) had received antiretroviral therapy prior to or at the time of admission. No information was available regarding antiretroviral therapy for the other six patients.

\section{Health condition}

Most hospitalisations were primarily for the management of bronchiolitis $(46.0 \%)$, followed by pneumonia $(36.5 \%)$,

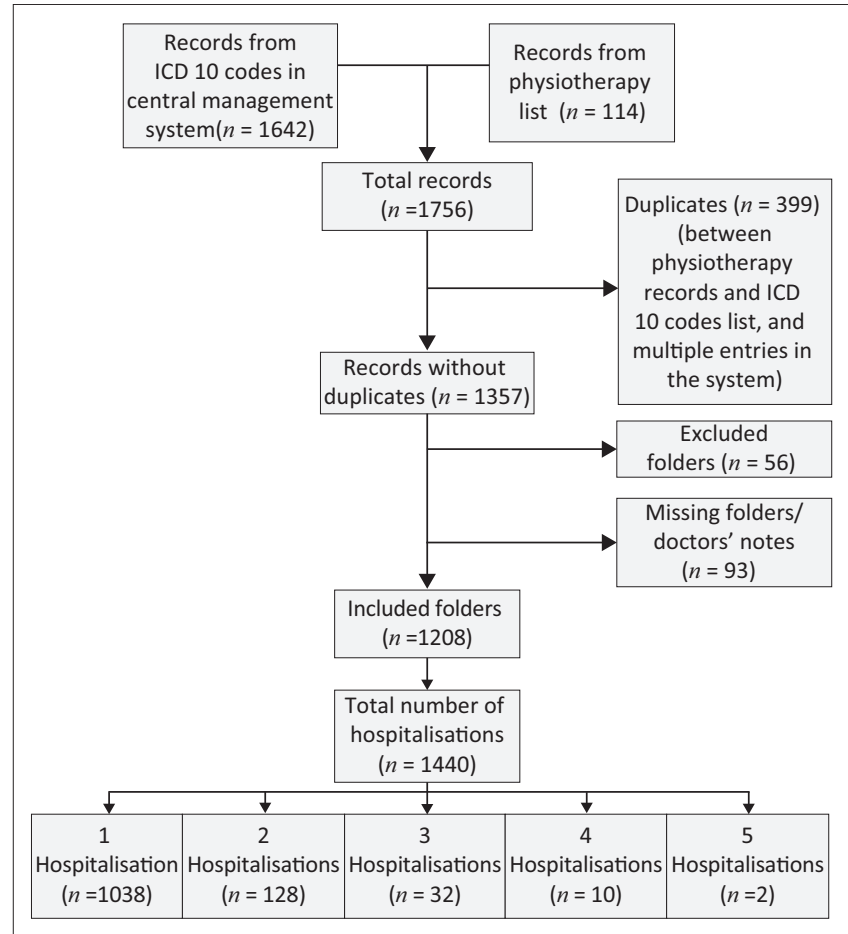

FIGURE 1: Folder review flow chart. 
unspecified acute LRTI (10.0\%) and other conditions (0.2\%). No primary diagnosis of LRTI was documented in 106 (7.4\%) cases; however, the discharge diagnosis included LRTI. After extensively reviewing the clinical course, these children were presumed to have developed nosocomial LRTI during their hospital stay.

Positive sputum or blood cultures were available in 245 admissions (17.0\%). Table 2 presents the prevalence of associated organisms, for each diagnostic category, as identified on sputum or blood culture. One child in the category 'other' tested positive for respiratory syncytial virus (RSV) and cytomegalovirus.

The majority of children presented with tachypnoea and tachycardia on admission. Signs of respiratory distress were

TABLE 1: Demographic characteristics of the included children.

\begin{tabular}{lcc}
\hline Characteristic & \multicolumn{2}{c}{ Outcome } \\
\cline { 2 - 3 } & $\boldsymbol{n}$ & $\%$ \\
\hline Age (months), median (IQR) & 7.6 & $2.8-19.0$ \\
Gender, male $(n)$ & 720 & 59.6 \\
Gestation, term $\geq 37$ weeks gestational age $(n)$ & 924 & 64.2 \\
HIV status $(n)$ & - & - \\
Positive & 35 & 2.9 \\
Negative & 937 & 77.6 \\
Exposed & 112 & 9.3 \\
Unknown & 124 & 10.3 \\
\hline
\end{tabular}

evident in 1361 hospitalisations (94.5\%), with tachypnoea being the most common (81.6\% of hospitalisations), followed by recessions (69.2\%). Other signs of distress were alar flaring $(23.5 \%)$, tracheal tug $(8.5 \%)$, head bobbing $(4.8 \%)$, cyanosis $(0.4 \%)$ and feeding problems $(0.4 \%)$. The median (IQR) temperature and peripheral oxygen saturation in room air at admission were $37.0^{\circ} \mathrm{C}\left(36.7^{\circ} \mathrm{C}-38.0^{\circ} \mathrm{C}\right)$ and $96.0 \%(94.0 \%-98.0 \%)$, respectively.

Children received non-invasive and/or invasive mechanical ventilation during 258 hospitalisations (17.9\%) (one-hundred and fifty children were diagnosed with pneumonia, 51 were diagnosed with bronchiolitis, 40 were diagnosed with presumed nosocomial LRTI and 17 were diagnosed with unspecified LRTI). Continuous positive airway pressure was the most common form of ventilation ( $n=234,90.7 \%$ ), followed by invasive intermittent positive pressure ventilation $(n=62$, $24.0 \%)$, pressure control ventilation $(n=12,4.7 \%)$, highfrequency oscillatory ventilation $(n=11,4.3 \%)$, bilevel positive airway pressure $(n=11,4.3 \%)$ and synchronised intermittent mechanical ventilation $(n=3,1.2 \%)$.

The median (IQR) duration of ventilator support was 3.0 (2.0-5.0) days.

Twenty-five children (2.1\%) had a known history of tuberculosis (TB). The episode of TB occurred at a median (IQR) of 8.2 (6.3-45.7) months prior to the first day of admission.

TABLE 2: Prevalence of viral and bacterial organisms, based on $n=245$ sputum/blood tests (multiple responses per test possible)

\begin{tabular}{|c|c|c|c|c|c|c|c|}
\hline \multirow[t]{2}{*}{ Category } & \multirow[t]{2}{*}{ Organism } & \multicolumn{2}{|c|}{ Total } & \multirow[t]{2}{*}{ Bronchiolitis, $n$} & \multirow[t]{2}{*}{ Pneumonia, $n$} & \multirow[t]{2}{*}{ LRTI, $n$} & \multirow{2}{*}{$\begin{array}{c}\text { Presumed } \\
\text { nosocomial, } n\end{array}$} \\
\hline & & $n$ & $\%$ & & & & \\
\hline \multirow[t]{12}{*}{ Viral } & RSV & 108 & 44.1 & 27 & 57 & 10 & 13 \\
\hline & Rhinovirus & 92 & 38.0 & 18 & 51 & 7 & 17 \\
\hline & Adenovirus & 79 & 32.2 & 19 & 36 & 11 & 12 \\
\hline & Boca virus & 32 & 13.1 & 9 & 16 & 4 & 3 \\
\hline & Parainfluenza & 25 & 10.2 & 5 & 14 & 5 & 1 \\
\hline & Influenza & 19 & 7.8 & 4 & 7 & 4 & 4 \\
\hline & Enterovirus & 17 & 6.9 & 2 & 13 & 1 & 1 \\
\hline & Human corona virus & 15 & 6.1 & 1 & 10 & 0 & 4 \\
\hline & Cytomegalovirus & 11 & 4.5 & 1 & 7 & 0 & 2 \\
\hline & Human metapneumovirus & 3 & 1.2 & 0 & 2 & 0 & 1 \\
\hline & Parvovirus & 1 & 0.4 & 1 & 0 & 0 & 0 \\
\hline & Total viral organisms & 402 & - & 87 & 213 & 42 & 58 \\
\hline \multirow[t]{15}{*}{ Bacterial } & Mycobacterium tuberculosis & 12 & 4.9 & 1 & 7 & 1 & 3 \\
\hline & Pseudomonas aeruginosa & 9 & 3.7 & 0 & 2 & 0 & 7 \\
\hline & Haemophilus influenzae & 8 & 3.3 & 1 & 0 & 1 & 6 \\
\hline & Staphylococcus aureus & 6 & 2.4 & 0 & 1 & 0 & 5 \\
\hline & Streptococcus pneumoniae & 4 & 1.6 & 0 & 1 & 0 & 3 \\
\hline & PJP & 4 & 1.6 & 0 & 4 & 0 & 0 \\
\hline & Acinetobacter baumannii & 3 & 1.2 & 0 & 1 & 0 & 2 \\
\hline & Escherichia coli & 3 & 1.2 & 0 & 2 & 0 & 1 \\
\hline & Methicillin-resistant Staphylococcus aureus & 2 & 0.8 & 0 & 1 & 0 & 1 \\
\hline & Moraxella & 2 & 0.8 & 0 & 1 & 0 & 1 \\
\hline & Enterobacter cloacae & 2 & 0.8 & 0 & 0 & 0 & 2 \\
\hline & Serratia marcescens & 1 & 0.4 & 1 & 0 & 0 & 0 \\
\hline & Stenotrophomonas maltophilia & 1 & 0.4 & 0 & 0 & 0 & 1 \\
\hline & Unspecified gram-positive bacteria & 10 & 4.1 & 0 & 7 & 0 & 3 \\
\hline & Total bacterial organisms & 78 & - & 4 & 31 & 3 & 40 \\
\hline Total & & 480 & - & 91 & 244 & 45 & 98 \\
\hline
\end{tabular}

RSV, respiratory syncytial virus; PJP, Pneumocystis jirovecii pneumonia; LRTI, lower respiratory tract infection. 
Most children (82.1\%) had not been hospitalised for a prior respiratory disease before their first admission during the study period. For those who were hospitalised previously, the most recent hospitalisations occurred at a median (IQR) of 8.9 (4.8-14.6) months prior to the index admission.

Of the total sample, $52.6 \%$ had one or more clinically significant comorbidity(ies) during at least one of the hospitalisations in the study period. Respiratory comorbidities were most common (17.6\%), followed by cardiac (16.4\%) and metabolic/nutritional comorbidities (13.9\%). The common chronic and acute comorbidities (present in 10 or more children) are presented in Table 3.

A significant association was seen between the primary diagnostic category and the presence of at least one chronic comorbidity (Yates $X^{2}=170.5, p<0.001$ ) or acute comorbidity
(Yates $X^{2}=55.7, p<0.001$ ), with the highest proportion of comorbidities seen in children admitted with pneumonia.

\section{Airway clearance therapy}

In total, 108 cases were referred to the physiotherapy department (7.5\%). Airway clearance therapy was given in 85 of these cases $(5.9 \%$ ) (forty-seven cases were diagnosed with presumed nosocomial LRTI, 22 were diagnosed with pneumonia, 14 were diagnosed with bronchiolitis and two were diagnosed with LRTI), with the majority of ACT interventions (75.9\%) started during the first week of hospitalisation. Approximately, half the patients received bidaily treatment $(49.4 \%)$, one received more than bidaily ACT (1.2\%) and the remainder (47.1\%) received daily ACT. Airway clearance therapies were performed for a median (IQR) of 3.0 (1.0-6.0) days per admission. Table 4 presents an overview of the ACT modalities performed.

TABLE 3: Most common chronic (based on $n=1208$ children) and acute ( $n=1440$ hospitalisations) comorbidities seen in children hospitalised with a lower respiratory tract infection.

\begin{tabular}{|c|c|c|c|c|}
\hline Disease category & Acute or chronic & Comorbidity & $n$ & Percentage \\
\hline \multirow[t]{11}{*}{ Respiratory } & Chronic & Asthma & & \\
\hline & & Proven & 49 & 4.1 \\
\hline & & Suspected & 7 & 0.6 \\
\hline & & Upper airway obstruction & 27 & 2.1 \\
\hline & & Chronic lung disease, not further specified & 11 & 0.9 \\
\hline & Acute & Upper respiratory tract infection (URTI) & 47 & 3.3 \\
\hline & & Apnoea & 16 & 1.1 \\
\hline & & Pertussis & & \\
\hline & & Proven & 13 & 0.9 \\
\hline & & Suspected & 2 & 0.1 \\
\hline & & Bronchospasm & 11 & 0.8 \\
\hline \multirow[t]{7}{*}{ Cardiovascular } & Chronic & Patent ductus arteriosus & & \\
\hline & & Proven & 23 & 1.9 \\
\hline & & Suspected & 1 & 0.1 \\
\hline & & Ventricular septal defect & 22 & 1.8 \\
\hline & & Atrioventricular septal defect & 15 & 1.2 \\
\hline & Acute & Anaemia & 107 & 7.4 \\
\hline & & Sepsis & 72 & 5.0 \\
\hline \multirow[t]{4}{*}{ Neurological } & Chronic & Seizures or epilepsy & 35 & 2.9 \\
\hline & & Cerebral palsy (CP) & 23 & 1.9 \\
\hline & & Neuromuscular disorder (NMD) & 13 & 1.1 \\
\hline & Acute & Meningitis & 10 & 0.7 \\
\hline Genetic disorder & Chronic & Trisomy 21 & 19 & 1.6 \\
\hline Musculoskeletal & Chronic & Scoliosis & 11 & 0.9 \\
\hline \multirow[t]{2}{*}{ Gastrointestinal } & Chronic & Gastro-oesophageal reflux disorder (GORD) & 51 & 4.2 \\
\hline & Acute & Acute gastroenteritis & 91 & 6.3 \\
\hline Dermatological & Chronic & Eczema & 33 & 2.7 \\
\hline Ear, nose and throat (ENT) & Acute & Otitis media & 24 & 1.7 \\
\hline \multirow[t]{2}{*}{ Metabolic/nutritional } & Acute & Failure to thrive & 151 & 10.5 \\
\hline & & Hypothyroidism & 10 & 0.7 \\
\hline Ophthalmology & Acute & Conjunctivitis & 18 & 1.3 \\
\hline \multirow[t]{4}{*}{ Other } & Chronic & Developmental delay & 45 & 3.7 \\
\hline & & Neonatal jaundice & 34 & 2.8 \\
\hline & & Dysmorphic features & 14 & 1.2 \\
\hline & & $\begin{array}{l}\text { Maternal drug abuse during pregnancy or exposure of the } \\
\text { child to toxic fumes caused by drugs }\end{array}$ & 10 & 0.8 \\
\hline
\end{tabular}


TABLE 4: Frequency of performed airway clearance therapies in the 83 cases receiving airway clearance therapies (multiple airway clearance therapies could be used per case).

\begin{tabular}{lcc}
\hline Treatment modality & $\boldsymbol{n}$ & Percentage \\
\hline Vibrations & 69 & 81.2 \\
MPD & 46 & 54.1 \\
Percussions/clapping & 32 & 37.6 \\
Deep breathing exercises & 21 & 24.7 \\
Active gross motor exercises & 17 & 20.0 \\
ACBT & 11 & 12.9 \\
Thoracic compressions & 7 & 8.2 \\
FET/Huff & 6 & 7.1 \\
Bubble PEP & 6 & 7.1 \\
AAD & 5 & 5.9 \\
Oscillating PEP & 3 & 3.5 \\
Blowing bubbles & 3 & 3.5 \\
Chest wall shaking & 1 & 1.2 \\
PEP & 0 & 0.0 \\
AD & 0 & 0.0 \\
\hline Total & $\mathbf{2 2 7}$ & - \\
\hline
\end{tabular}

MPD, modified postural drainage; $A C B T$, active cycle of breathing; FET, forced expiratory technique; PEP, positive expiratory pressure; $A A D$, assisted autogenic drainage; $A D$, autogenic drainage.

Transient desaturation occurred in six cases (7.2\%) (three desaturated to levels between $85 \%$ and $89 \%$, and three desaturated to below 85\%), during or immediately after ACT: during positioning in left side lying $(n=2)$, suctioning $(n=1)$, suctioning and vibrations $(n=1)$, percussions and vibrations $(n=1)$ and breathing exercises in the sitting position $(n=1)$. One child presented with right upper lobe collapse more than an hour after ACT. No other adverse events associated with ACT were reported.

A significant association was found between the primary diagnostic category and whether or not ACT was given (Yates $\chi^{2}=312.5, p<0.001$ ). Airway clearance therapies were most often given for children hospitalised with presumed nosocomial infections and pneumonia, and least often in children admitted with bronchiolitis. Furthermore, children with bacterial organisms were more likely to receive ACT (Yates $\chi^{2}=158.3, p<0.001$ ).

The most predictive factors for receiving ACT were chronic respiratory comorbidities, neuromuscular disorders, history of previous hospitalisation for a respiratory condition and receiving mechanical ventilation during admission $(50.0 \%$ of the ventilated patients received ACT). This final logistic regression model provided the best prediction with a -2 Log likelihood ratio of $514.1(p<0.001)$.

\section{Patient outcomes}

The median (IQR) length of hospitalisation was 2.3 (1.5-5.0) days, with a significant difference in the mean days of hospitalisation amongst the different diagnostic groups $(p<0.001)$. A post-hoc Tukey's test identified a significant longer duration of hospitalisation for children with presumed nosocomial infection (mean [SD] 14.3 [18.5] days), and children hospitalised for bronchiolitis had a shorter hospital stay (mean [SD] 2.9 [4.0] days) than children in the other diagnostic categories (pneumonia and unspecified LRTI mean [SD], 6.0 [8.9] days and 5.4 [12.4] days, respectively).
TABLE 5: Multiple regression outcomes for duration of hospitalisation.

\begin{tabular}{llcc}
\hline Step & Predicting factors & $\boldsymbol{R}^{2}$ & Change in $\boldsymbol{R}^{2}$ \\
\hline 1 & Mechanical ventilation & 0.194 & 0.194 \\
2 & + chronic heart disease & 0.332 & 0.138 \\
3 & + airway clearance therapy (ACT) & 0.397 & 0.065 \\
4 & + oxygen saturation on admission & 0.429 & 0.032 \\
5 & + genetic disease & 0.451 & 0.022 \\
6 & + cerebral palsy & 0.462 & 0.011 \\
7 & + acute comorbidities & 0.471 & 0.008 \\
\hline
\end{tabular}

TABLE 6: Description of the deceased patients.

\begin{tabular}{|c|c|c|c|}
\hline Participant & $\begin{array}{l}\text { Primary } \\
\text { diagnosis }\end{array}$ & $\begin{array}{l}\text { Age at time } \\
\text { of death }\end{array}$ & Comorbidities \\
\hline 1 & Pneumonia & 16.5 years & $\begin{array}{l}\text { Liver transplant in 2008: chronic liver } \\
\text { reject, sepsis, anaemia, acute } \\
\text { gastroenteritis }\end{array}$ \\
\hline 2 & $\begin{array}{l}\text { Presumed } \\
\text { nosocomial LRTI }\end{array}$ & 12.4 years & $\begin{array}{l}\text { Congenital muscular dystrophy, } \\
\text { kyphoscoliosis, GORD, developmental delay }\end{array}$ \\
\hline 3 & LRTI & 10.9 years & $\begin{array}{l}\text { CP (spastic quadriplegia), seizures, } \\
\text { scoliosis, microcephaly, cortical blindness, } \\
\text { GORD, upper airway obstruction }\end{array}$ \\
\hline 4 & $\begin{array}{l}\text { Presumed } \\
\text { nosocomial LRTI }\end{array}$ & 7.5 years & $\begin{array}{l}\text { CP (spastic quadriplegia), congenital } \\
\text { dandy-walker malformation, } \\
\text { hydrocephalus, seizures, developmental } \\
\text { delay, anaemia, sepsis }\end{array}$ \\
\hline 5 & Pneumonia & 5.0 years & $\begin{array}{l}\text { Trisomy } 21 \text {, multiorgan failure, seizures, } \\
\text { upper airway obstruction, GORD, history } \\
\text { of rickets }\end{array}$ \\
\hline 6 & $\begin{array}{l}\text { Presumed } \\
\text { nosocomial LRTI }\end{array}$ & 4.5 years & $\begin{array}{l}\text { Traumatic brain injury because of } \\
\text { pedestrian-vehicle-accident, brain stem } \\
\text { death }\end{array}$ \\
\hline 7 & Pneumonia & 1.8 years & $\begin{array}{l}\text { Pulmonary haemorrhage, bronchospasm, } \\
\text { acute gastroenteritis, sepsis }\end{array}$ \\
\hline 8 & $\begin{array}{l}\text { Presumed } \\
\text { nosocomial LRTI }\end{array}$ & 3.8 months & $\begin{array}{l}\text { SMA I, failure to thrive, acute } \\
\text { gastroenteritis }\end{array}$ \\
\hline 9 & $\begin{array}{l}\text { Presumed } \\
\text { nosocomial LRTI }\end{array}$ & 2.8 months & $\begin{array}{l}\text { Trisomy } 21 \text {, atrioventricular septal defect, } \\
\text { chylothorax, developmental delay }\end{array}$ \\
\hline 10 & $\begin{array}{l}\text { Presumed } \\
\text { nosocomial LRTI }\end{array}$ & 1.9 months & $\begin{array}{l}\text { Trisomy 13, dysmorphic, polydactyly, } \\
\text { bilateral cataract, URTI, failure to thrive, } \\
\text { atrioventricular septal defect }\end{array}$ \\
\hline
\end{tabular}

GORD, gastro-oesophageal reflux disorder; LRTI, lower respiratory tract infection; CP, cerebral palsy; SMA, spinal muscular atrophy; URTI, upper respiratory tract infection.

Forward stepwise multiple regression analysis was performed to identify factors that influenced the duration of hospitalisation. The final model accounted for $47.1 \%$ of the variance. Mechanical ventilation was the factor that influenced the length of hospital stay the most, explaining 19.4\% of variance. It is also seen that children who received ACT stayed in hospital for longer (explaining 6.5\% of the variance). Furthermore, chronic comorbidities were more predictive of a longer hospital stay than acute comorbidities (Table 5).

In total, 10 children $(0.7 \%)$ died while hospitalised during the study period (Table 6). A significant association between mortality rate and diagnostic category was found (Yates $\left.\chi^{2}=45.5, p<0.001\right)$. Mortality was higher for children who developed presumed nosocomial infections, followed by pneumonia, compared to other diagnostic categories. There was a significant association between delivery of ACT and mortality (Yates $\left.\chi^{2}=41.96 ; p<0.001\right)$.

\section{Discussion}

The majority of children admitted with LRTIs were younger than 1 year of age, male, HIV uninfected, and born at term, similar to other published studies (Forster et al. 2004:709-716; Hasan et al. 2014:e45-e52; Hatipoglu et al. 2011:508-516; Wolf et al. 2006:320-324). 
The disproportionate gender representation may relate to differences in sex hormones, influencing immune response through lymphocyte and macrophage function (Muenchhoff \& Goulder 2014:S120-126). Furthermore, male infants have narrower peripheral airways compared to female infants, possibly contributing to increased LRTI severity (Tepper et al. 1986:513-519).

In our study, the primary diagnosis of bronchiolitis and pneumonia was made in $46.0 \%$ and $36.5 \%$ of cases, respectively. This is similar to previous studies that reported between $55 \%$ and $60 \%$ of in-patients as having bronchiolitis and 35\% - 45\% diagnosed with pneumonia (Forster et al. 2004:709-716; Hatipoglu et al. 2011:508-516). More viral than bacterial organisms were isolated. This confirms the results of a previous South African study, where human rhinovirus, RSV and adenovirus were most often identified in children with LRTI (White et al. 2016:443-445). Hasan et al. (2014:e45e52) reported that RSV was the most common viral agent, followed by rhinovirus. This is the same as our results, albeit in different proportions $(19.5 \%$ and $18.7 \%$, respectively, in Hasan et al.'s report compared to $44.1 \%$ and $38.0 \%$ here). A study conducted on Turkish children with viral LRTI also reported RSV as the main pathogen (55.6\%) in children younger than 1 year of age, followed by parainfluenza, which was the most common viral isolate in older children (Hatipoglu et al. 2011:508-516). We found Mycobacterium tuberculosis to be the most common bacterial organism (4.9\%), followed by Klebsiella pneumoniae (4.5\%). Another South African study reported Acinetobacter baumannii as the most common bacterial organism, followed by Klebsiella pneumoniae (20.6\%) (Ghani et al. 2012:e275-e281). Although our rate for Klebsiella pneumoniae identification was similar to that reported by Hasan et al. (2014:e45-e52) (4.1\%), it was only the seventh most common bacterial agent in the latter study. Our study is limited by the low rate of available sputum/blood cultures, with no standardisation of sampling, potentially overestimating the proportions of some organisms whilst missing others.

Ventilator support was given during $17.9 \%$ of the hospitalisations. This proportion is higher than a previous report, where the proportion of children receiving mechanical ventilation was only 1.0\% (Wolf et al. 2006:320-324). However, the study did not specify whether non-invasive ventilation was included, in addition to invasive mechanical ventilation (Wolf et al. 2006:320-324).

One or more comorbidities were present in just over half the cases, with respiratory problems the most common, followed by cardiovascular disorders. In a study by Wang, Law and Stephens (1995:212-219) on Canadian children hospitalised with RSV LRTI, the proportion of comorbidities (22.6\%) was lower than here $(52.6 \%)$. This might relate to different methodologies and comorbidity selection (Wang et al. 1995:212-219). Furthermore, we included any LRTI, not merely RSV LRTI.
Of the $5.9 \%$ of hospitalisations that received ACT, the majority of treatments were commenced in the first week of hospitalisation. However, seven children only received ACT more than 2 weeks after admission. Vibrations and modified postural drainage (excluding the head-down position) were performed most often, with $49.4 \%$ of the children receiving bidaily treatment. Airway clearance therapy is not recommended as routine management for children with bronchiolitis, by the American Association for Paediatrics, based on the results found in a systematic review by Figuls et al. (American Academy of Pediatrics 2014:e1474-e1502; Figuls et al. 2016:CD004873). Although the National Institute for Health and Care Excellence agrees with this recommendation for most children, they do specify that ACT can be given to children with bronchiolitis with relevant comorbidities, if requiring ACT for facilitation of mucus clearance (Caffrey Osvald \& Clarke 2015:1-3). In our study, ACT was given less frequently to children with bronchiolitis or unspecified LRTI, which conforms to the guidelines for the management of children with bronchiolitis.

In children with pneumonia, little evidence is available regarding the use of ACT as part of disease management. Two systematic reviews have been published, including up to three randomised controlled trials on this topic, without clear recommendations for or against the use of ACT in these children (Chaves et al. 2013:CD010277; Corten et al. 2015:256). However, small benefits have been reported in other studies (Abdelbasset \& Elnegamy 2015:219-226; Santos et al. 2009:23), indicating the need for further research in this field. The children who were most likely to receive ACT were those with bacterial nosocomial infections or pneumonia and those with chronic comorbidities. Therefore, it is recommended that further research be conducted on the use and safety of $\mathrm{ACT}$ in children presenting with these conditions.

Adverse events of ACT are rarely mentioned and described in the literature, which was also the case in our study. Six children did, however, desaturate during ACT. One child presented with a lobar collapse more than one hour after ACT, and given the time delay, it is unlikely that this adverse event was directly related to ACT. Owing to the observation of desaturation during $\mathrm{ACT}$, monitoring of peripheral oxygen saturation is recommended during the performance of ACT. A study on the use of ACT in children with bronchiolitis mentioned that no adverse events occurred; however, it is unclear as to which adverse events were under consideration (Postiaux et al. 2011:989-994). As the rate of adverse events was low in our study and very little literature is available on this topic, ACT appears to be safe for use in children with LRTI, but this requires confirmation in prospective clinical studies.

Chronic comorbidities were the most likely predictors for receiving ACT during hospitalisation. Children with presumed nosocomial infections were more likely to receive ACT, followed by children hospitalised for pneumonia. These data, however, may have been biased because the majority of children classified as presumed nosocomial infections were 
included based on physiotherapy referral and not through diagnostic code search identification. In children hospitalised for pneumonia, multiple comorbidities were identified, for which ACT might be indicated. Children with positive bacterial culture were treated more often by the physiotherapists than children with viral isolates. No previous studies have investigated the association between ACT and isolated organisms; therefore, confirmation of the results in a larger prospective study is recommended.

Children were hospitalised for a median of 2.3 days; however, children with presumed nosocomial infections were hospitalised for a significantly longer duration (14.3 days). In addition to clinical outcomes, cost prevention and high demands for hospital beds in lower-resourced countries could be contributing factors for short duration of hospital stay (Argent et al. 2014:7-14). However, three randomised controlled trials on children hospitalised with pneumonia reported a median duration of hospital stay of six to eight days (Corten et al 2018:e1690; Lukrafka et al. 2012:967-971; Paludo et al. 2008:791-794), which is similar to the duration of hospitalisation for pneumonia in our study.

The length of hospital stay was associated with whether or not children received ventilator support; had chronic heart conditions; received ACT, desaturation on admission; and had cerebral palsy, genetic disorder or acute comorbidities. In a study conducted by Rodriguez et al. (2014:269-276), predictors for disease severity in children with RSV LRTI, partially based on length of hospital stay, were aged younger than 6 months, born prematurely, with a pre-existing lung disease or congenital cardiac disease. Our finding that receiving ACT was associated with increased duration of hospital stay may reflect the increased likelihood of receiving ACT in those who developed nosocomial infections (Green et al. 2015:305-312).

However, the RCT by Lukrafka et al. also reported a median 2 days longer hospital stay in children who received ACT, compared to controls, which was not statistically significant, possibly owing to insufficient sample size (Lukrafka et al. 2012:967-971). Other studies have not reported significant differences for length of stay when receiving ACT in children hospitalised with pneumonia (Corten et al. 2018:e1690; Paludo et al. 2008:791-794). Prospective studies are recommended to confirm these results and to determine causality.

Pneumonia is still the most common cause for mortality in children younger than 5 years of age worldwide (Liu et al. 2015:430-440). In our study, the overall mortality rate for children with an LRTI was low; however, a greater proportion of children with presumed nosocomial infection (5.7\%) died. The mortality rate for children with a clinical diagnosis of pneumonia was $0.6 \%$. These mortality rates, although slightly higher, are comparable to the rates found in children younger than 5 years hospitalised with acute LRTI in rural Thailand, with $0.3 \%$ overall mortality rate (Hasan et al. 2014:e45-e52). All children included in our study, who died during the study period, presented with multiple comorbidities and seven of the 10 children were older than 4 years of age. The cause of death could therefore be multifactorial and not solely attributed to LRTI. Airway clearance therapy was associated with an increased mortality rate, which has not been previously reported. However, causality cannot be determined on the basis of this study design. Considering most children admitted with pneumonia had comorbidities, this may explain the higher mortality observed in this group.

\section{Conclusion}

This study revealed that a relatively small proportion of children with LRTI received ACT. Airway clearance therapy was mostly applied in children with presumed nosocomial infections, followed by pneumonia. Given the paucity of high-level evidence, ACT is therefore used in clinical practice based on physicians' and physiotherapists' expert opinion. It is therefore recommended that more research regarding ACT in children with nosocomial infections and pneumonia be conducted. This is particularly important considering that the duration of hospitalisation was longer and the mortality rate was higher in children with nosocomial infections and pneumonia, compared to those admitted with other LRTIs, especially bronchiolitis.

This study also found that ACT, as performed at this research site, appears relatively safe to perform in children with LRTI. However, the study was not designed or powered to determine safety, and further prospective, controlled clinical trials are recommended to confirm this finding. It is recommended that peripheral oxygen saturation be continuously monitored during ACT, in order to promptly identify desaturation and implement appropriate management.

As more than half the children included in this study presented with comorbidities, research is warranted to investigate the use of ACT in children hospitalised with LRTI and comorbidities, both chronic and acute.

\section{Acknowledgements}

The authors would like to thank Ms Ebrahim for her assistance in collecting the data for this study. They would also like to thank the medical records office of Red Cross War Memorial Children's Hospital for their assistance in retrieving folders for the study.

\section{Competing interests}

The authors have declared that no competing interest exists.

\section{Authors' contributions}

L.C. collected and analysed the data and wrote the initial drafts of the paper under the supervision of B.M. Both authors contributed to protocol development and results interpretation. B.M. also contributed to the write-up and approved the final version of the manuscript. 


\section{Funding information}

Dr Corten received the Margaret Roper Scholarship from the Division of Physiotherapy for her PhD study at the University of Cape Town. The Department of Paediatrics and Child Health research award (University of Cape Town) provided funds for this study.

\section{Data availability statement}

Data sharing is not possible as no ethical approval was obtained to share sensitive data from a vulnerable patient population.

\section{Disclaimer}

The views and opinions expressed in this article are those of the authors and do not necessarily reflect the official policy or position of any affiliated agency of the authors.

\section{References}

Abdelbasset, W. \& Elnegamy, T., 2015, 'Effect of chest physical therapy on pediatrics hospitalized with pneumonia', International Journal of Health and Rehabilitation Sciences 4(4), 219-226. https://doi.org/10.5455/ijhrs.000000095

American Academy of Pediatrics, 2014, 'Clinical practice guideline: The diagnosis, management, and prevention of bronchiolitis', Pediatrics 134(5), e1474-e1502. https://doi.org/10.1542/peds.2014-2742

Argent, A.C., Ahrens, J., Morrow, B.M., Reynolds, L.G., Hatherill, M., Salie, S. et al., 2014 'Pediatric intensive care in South Africa: An account of making optimum use of 'Pediatric intensive care in South Africa: An account of making optimum use of
limited resources at the Red Cross War Memorial Children's Hospital', Pediatric limited resources at the Red Cross War Memorial Children's Hospital', Pediatric
Critical CareMedicine 15(1), 7-14. https://doi.org/10.1097/PCC.0000000000000029

Caffrey Osvald, E. \& Clarke, J.R., 2015, 'NICE clinical guideline: Bronchiolitis in children', Archives of Disease in Childhood - Education \& Practice Edition 101(1), 1-3. https://doi.org/10.1136/archdischild-2015-309156

Chaves, G., Fregonezi, G.A., Dias, F.A., Ribeiro, C.T., Guerra, R.O., Freitas, D.A. et al., 2013, 'Chest physiotherapy for pneumonia in children (review)', Cochrane Database of Systematic Reviews 20(9), CD010277. https://doi.org/10.1002/ 14651858.CD010277.pub2

Corten, L., Jelsma, J., Human, A., Rahim, S. \& Morrow, B.M., 2018, 'Assisted autogenic drainage in infants and young children hospitalized with uncomplicated pneumonia a pilot study', Physiotherapy Research International 23(1), e1690. https://doi.org/ $10.1002 /$ pri.1690

Corten, L., Jelsma, J. \& Morrow, B.M., 2015, 'Chest physiotherapy in children with acute bacterial pneumonia', South African Journal of Physiotherapy 71(1), \#256. https://doi.org/10.4102/sajp.v71i1.256

Figuls, M.R., Giné-Garriga, M., Granados Rugeles, C., Perrotta, C. \& Vilaró, J., 2016, 'Chest physiotherapy for acute bronchiolitis in paediatric patients between 0 and 24 months old', The Cochrane Library 2(2), CD004873. https://doi. org/10.1002/14651858.CD004873.pub5

Fink, J., 2007, 'Forced expiratory technique, directed cough, and autogenic drainage', Respiratory Care 52(9), 1210-1221. Viewed 07 February 2013, from https://www. rcjournal.com/contents/09.07/09.07.1210.pdf.

Forster, J., Ihorst, G., Rieger, C.H., Stephan, V., Frank, H.D., Gurth, H. et al., 2004 , 'Prospective population-based study of viral lower respiratory tract infections in children under 3 years of age (the PRI.DE study)', European Journal of Pediatrics 163(12), 709-716. https://doi.org/10.1007/s00431-004-1523-9

Ghani, A.S., Morrow, B.M., Hardie, D.R. \& Argent, A.C., 2012, 'An investigation into the prevalence and outcome of patients admitted to a pediatric intensive care unit with viral respiratory tract infections in Cape Town, South Africa', Pediatric Critical Care Medicine 13(5), e275-e281. https://doi.org/10.1097/PCC.0b013e3182417848
Green, N., Johnson, A.P., Henderson, K.L., Muller-Pebody, B., Thelwall, S., Robotham, J.V et al. 2015, 'Quantifying the burden of hospital-acquired bloodstream infection in children in England by estimating excess length of hospital stay and mortality using a multistate analysis of linked, routinely collected data', Journal of the Pediatric Infectious Diseases Society 4(4), 305-312. https://doi.org/10.1093/ jpids/piu073

Hasan, R., Rhodes, J., Thamthitiwat, S., Olsen, S.J., Prapasiri, P., Naorat, S. et al., 2014, 'Incidence and etiology of acute lower respiratory tract infections in hospitalized children younger than 5 years in rural Thailand', Pediatric Infectious Disease Journal 33(2), e45-e52. https://doi.org/10.1097/INF.00000 00000000062

Hatipoglu, N., Somer, A., Badur, S., Unüvar, E., Akçay-Ciblak, M., Yekeler, E. et al., 2011, 'Viral etiology in hospitalized children with acute lower respiratory tract infection', Turkish Journal of Pediatrics 53(5), 508-516. Viewed 06 February 2017, from https://www.turkishjournalpediatrics.org/uploads/pdf_TJP_966.pdf.

Liu, L., Oza, S., Hogan, D., Perin, J., Rudan, I., Lawn, J.E. et al., 2015, 'Global, regional, and national causes of child mortality in 2000-13, with projections to inform post2015 priorities: An updated systematic analysis', The Lancet 385(9965), 430-440. https://doi.org/10.1016/S0140-6736(14)61698-6

Lukrafka, J., Fuchs, S. \& Fischer, G., 2012, 'Chest physiotherapy in paediatric patients hospitalised with community-acquired pneumonia: A randomised clinical trial', Archives of Disease in Childhood 97(11), 967-971. https://doi.org/10.1136/ archdischild-2012-302279

Morrow, B.M., 2019, 'Airway clearance therapy in acute paediatric respiratory illness: A state-of-the-art review', South African Journal of Physiotherapy 75(1), 1-12. https://doi.org/10.4102/sajp.v75i1.1295

Moura Da Silva, P., Freitas, D.A., Silva Chaves, G.S., França Mendes, R.E., Fernandes de Macêdo, T.M. \& Pereira Pinto de Mendonça, K.M., 2015, 'Chest physiotherapy for pneumonia in children: A systematic review', Physiotherapy 101, eS1052-eS1053. https://doi.org/10.1016/j.physio.2015.03.1931

Muenchhoff, M. \& Goulder, P.J.R., 2014, 'Sex differences in pediatric infectious diseases', Journal of Infectious Diseases 209(suppl 3), S120-S126. https://doi. org/10.1093/infdis/jiu232

Paludo, C., Zhang, L., Lincho, C.S., Lemos, D.V., Real, G.G. \& Bergamin, J.A., 2008, 'Chest physical therapy for children hospitalised with acute pneumonia: A randomised controlled trial', Thorax 63(9), 791-794. https://doi.org/10.1136/ thx.2007.088195

Postiaux, G., Louis, J., Labasse, H.C., Gerroldt, J., Kotik, A.C., Lemuhot, A. et al., 2011, 'Evaluation of an alternative chest physiotherapy method in infants with respiratory syncytial virus bronchiolitis', Respiratory Care 56(7), 989-994. https:// doi.org/10.4187/respcare.00721

Rodriguez, D.A., Rodríguez-Martínez, C.E., Cárdenas, A.C., Quilaguy, I.E., Mayorga, L.Y., Falla, L.M. et al., 2014, 'Predictors of severity and mortality in children hospitalized with respiratory syncytial virus infection in a tropical region', Pediatric Pulmonology 49(3), 269-276. https://doi.org/10.1002/ppul.22781

Santos, C., Ribeiro, M.A.G.D.O., Ribeiro, J. \& Morcillo, A., 2009, 'Respiratory physiotherapy in children with community-acquired pneumonia', Canadian Journal of Respiratory Therapy 45(3), 23. Viewed 26 April 2013, from https:// www.cjrt.ca/download/2009-volume-45-number-3/?wpdmdl=76.

Tepper, R.S., Morgan, W.J., Cota, K., Wright, A., Taussig, L.M. \& GHMA Pediatricians, 1986, 'Physiologic growth and development of the lung during the first year of life', The American Review of Respiratory Disease 134(3), 513-519. Viewed 03 March 2017, from http://www.atsjournals.org.ezproxy.uct.ac.za/doi/ abs/10.1164/arrd.1986.134.3.513.

Wang, E.E.L., Law, B.J. \& Stephens, D., 1995, 'Pediatric Investigators Collaborative Network on Infections in Canada (PICNIC) prospective study of risk factors and outcomes in patients hospitalized with respiratory syncytial viral lower respiratory tract infection', The Journal of Pediatrics 126(2), 212-219. https://doi. org/10.1016/S0022-3476(95)70547-3

White, D.A., Madhi, S.A., Jeena, P.A., Zar, H.J., Morrow, B.M., Masekela, R. et al., 2016, 'Acute viral bronchiolitis in South Africa: Viral aetiology and clinical epidemiology' South African Medical Journal 106(5), 443-445. https://doi.org/10.7196/SAMJ. 2016.v106i5.10444

Wolf, D.G., Greenberg, D., Kalkstein, D., Shemer-Avni, Y., Givon-Lavi, N., Saleh, N. et al., 2006, 'Comparison of human metapneumovirus, respiratory syncytial virus and influenza A virus lower respiratory tract infections in hospitalized young children', influenza A virus lower respiratory tract infections in hospitalized young children',
Pediatric Infectious Disease Journal 25(4), 320-324. https://doi.org/10.1097/01. Pediatric Infectious Disease
inf.0000207395.80657.cf 